\title{
Effects of Bedtime Very Low Dose Cyclobenzaprine on Symptoms and Sleep Physiology in Patients with Fibromyalgia Syndrome: A Double-blind Randomized Placebo-controlled Study
}

\author{
HARVEY MOLDOFSKY, HERBERT W. HARRIS, W. TAD ARCHAMBAULT, TERENCE KWONG, \\ and SETH LEDERMAN
}

ABSTRACT. Objective. To determine the effects of bedtime very low dose (VLD) cyclobenzaprine (CBP) on symptoms and sleep physiology of patients with fibromyalgia (FM), unrefreshing sleep, and the $\alpha$-nonREM sleep electroencephalographic (EEG) anomaly at screening.

Methods. Of 37 patients with FM in the screened population, 36 were randomized and treated in this 8-week, double-blind, placebo-controlled, dose-escalating study of VLD CBP 1-4 mg at bedtime. We evaluated changes in subjective symptoms including pain, tenderness, fatigue, mood [Hospital Anxiety and Depression Scale (HAD)], and objective EEG sleep physiology (at screening, baseline, and Weeks 2, 4, and 8).

Results. In the VLD CBP-treated group $(\mathrm{n}=18)$ over 8 weeks, musculoskeletal pain and fatigue decreased, tenderness improved; total HAD score and the HAD depression subscore decreased; patient-rated and clinician-rated fatigue improved. In the placebo-treated group $(n=18)$, none of these outcome measures changed significantly. Compared to placebo at 8 weeks, VLD CBP significantly improved pain, tenderness, and the HAD Depression subscore. Analysis of cyclic alternating pattern (CAP) sleep EEG revealed that significantly more subjects in the VLD CBP group than the placebo group had increased nights of restorative sleep in which $\mathrm{CAP}_{\mathrm{A} 2+\mathrm{A} 3} / \mathrm{CAP}_{\mathrm{A} 1+\mathrm{A} 2+\mathrm{A} 3}=$ $\mathrm{CAP}_{\mathrm{A} 2+\mathrm{A} 3(\mathrm{Norm})} \leq 33 \%$. For VLD CBP-treated subjects, the increase in nights with $\mathrm{CAP}_{\mathrm{A} 2+\mathrm{A} 3 \text { (Norm) }}$ $\leq 33 \%$ was correlated to improvements in fatigue, total HAD score, and HAD depression score.

Conclusion. Bedtime VLD CBP treatment improved core FM symptoms. Nights with $\mathrm{CAP}_{\mathrm{A} 2+\mathrm{A} 3(\mathrm{Norm})} \leq 33 \%$ may provide a biomarker for assessing treatment effects on nonrestorative sleep and associated fatigue and mood symptoms in persons with FM. (First Release Sept 2 2011; J Rheumatol 2011;38:2653-63; doi:10.3899/jrheum.110194)

Key Indexing Terms:

FIBROMYALGIA

PAIN

SLEEP

CYCLOBENZAPRINE

Fibromyalgia syndrome (FM) is a common, chronic musculoskeletal pain disorder, diagnosed predominantly in women, that is characterized by widespread pain, increased sensitivity to pain (or tenderness) at multiple tender points, fatigue, unrefreshing sleep, and depressed $\operatorname{mood}^{1}$. Cyclobenzaprine (CBP) has been studied in FM in a number of randomized trials employing doses of $10-40 \mathrm{mg}$ per day,

From the Sleep Disorders Clinics of the Centre for Sleep and Chronobiology, University of Toronto, Toronto, Ontario, Canada.

Supported by TONIX Pharmaceuticals Inc., New York, New York, USA.

H. Moldofsky, MD, FRCPC, Director, Sleep Disorders Clinics of the Centre for Sleep and Chronobiology, University of Toronto; H.W. Harris, MD, PhD, TONIX Pharmaceuticals Inc.; W.T. Archambault, PhD, Virtu Stat Ltd., North Wales, PA, USA; T. Kwong, BASc (EE), Sleep Disorders Clinics of the Centre for Sleep and Chronobiology, University of Toronto; S. Lederman, MD, TONIX Pharmaceuticals Inc.

Address correspondence to Dr. H. Moldofsky, Sleep Disorders Clinics, Centre for Sleep and Chronobiology, University of Toronto, 340 College Street, Suite 580, Toronto, Ontario M5T 3A9, Canada.

E-mail: h.moldofsky@utoronto.ca

Full Release Article. For details see Reprints/Permissions at jrheum.org Accepted for publication June 7, 2011. with mixed results $2,3,4,5,6,7$. CBP is approved by the US Food and Drug Administration (FDA) for treating muscle spasm, which is not a feature of FM. However, CBP has gained wide use in the US without promotion to treat FM symptoms in a manner not sanctioned by the FDA, or "off-label." While CBP has been studied in FM at various doses and dosing schedules, it remains unclear whether CBP might be effective in the management of FM and if so, what dose or dosing schedule is optimal.

In randomized trials of FM, CBP at doses of $10-40 \mathrm{mg}$ per day has been associated with improvement in FM but also with side effects $2,3,4,5,6,7$. A metaanalysis of 5 randomized placebo-controlled trials with high-dose CBP, given at variable times during the day, showed an overall global improvement, a short-term modest improvement in pain, moderate improvement in sleep, and no improvement in fatigue or tender points ${ }^{8}$. Eighty-five percent of patients experienced untoward effects, commonly drowsiness, dizziness, and dry mouth. Carette, et al reported a double-blind,

Personal non-commercial use only. The Journal of Rheumatology Copyright @ 2011. All rights reserved. 
placebo-controlled study comparing CBP with amitriptyline and placebo that showed little efficacy with longterm use of the drugs ${ }^{7}$. Physician global assessment ratings, however, showed a significant beneficial effect of CBP vs placebo at 6 months $^{7}$.

Bedtime CBP dosing has several potential advantages over daytime dosing. High blood levels of CBP are associated with somnolence and other side effects. Bedtime dosing that provides lower blood levels of CBP the next day might reduce unwanted daytime somnolence. In addition, bedtime dosing of CBP may improve sleep quality. Anecdotal experience and systematic case study suggest that very low doses of CBP at bedtime may provide benefit to FM patients with reduced next-day somnolence ${ }^{9}$. These findings suggest that side effects of daytime CBP might overwhelm treatment effects. In addition, general principles of medicinal chemistry and pharmaceutical development favor the lowest effective dose as a means of optimizing safety, given the presumptive health risk of any pharmaceutical. Consequently, bedtime administration of very low dose (VLD) CBP, if effective, has the potential to provide a protocol for CBP administration in FM patients with improved tolerability and reduced risk of toxicity relative to higher doses.

The CBP products currently marketed for treating muscle spasm are not designed for bedtime use. The immediate-release product Flexeril ${ }^{\circledR}$ is recommended for tid dosing (5 $\mathrm{mg}$ or $10 \mathrm{mg}$ tablets tid), which results in relatively stable blood levels over 24 hours after several days of treatment ${ }^{10}$. The controlled-release CBP product Amrix ${ }^{\circledR}$ mimics, and flattens, the pharmacokinetic profile of tid immediate-release CBP, so that bedtime administration of Amrix results in only a modest increase in nighttime blood levels ${ }^{11}$. Consequently, achieving high nighttime and low daytime blood levels of CBP requires bedtime dosing of immediate-release CBP formulations.

FM is a chronic condition punctuated by exacerbations (or flares) with variable severity of symptoms. A number of potential factors have been proposed that may contribute to causing, exacerbating, or perpetuating FM symptoms, including psychological factors ${ }^{12,13,14}$, mechanical stresses in the cervical and lumbar spine ${ }^{15}$, muscle deconditioning ${ }^{16}$, neurotransmitter abnormalities ${ }^{17}$, disturbances in the chronobiology of sleep-wakefulness ${ }^{18}$, and seasonal variation, with an increase in symptoms during winter months in the United States ${ }^{19}$.

Several lines of evidence support the idea that FM is associated with hyperactivity of the sympathetic nervous system $^{20}$. Patients with FM have heart rate variation and sensitivity to orthostatic changes on tilt-table tests ${ }^{20,21}$. Patients have increased sensitivity to external noxious stimuli and complain of diminished tolerance to loud sounds, bright lights, strong odors, and extremes of temperature and/or pressure ${ }^{22}$. In addition, FM is typically associated with disturbed sleep $^{23}$, which may relate to hypervigilance and alarm signals associated with a hypersympathetic state.

Disturbed, unrefreshing sleep is a frequent complaint of patients with FM. The sleep disturbance has been characterized as nonrestful or nonrestorative sleep. Patients have an arousal disturbance during electroencephalographic (EEG) sleep, termed the $\alpha$-EEG non-rapid eye movement (nonREM) anomaly or arousal rhythm ${ }^{24}$. A relationship between sleep disturbance and some of the symptoms associated with FM was suggested by the observation that non-FM volunteers subjected to noise that artificially disrupted their nonREM sleep experienced a similar $\alpha$-EEG sleep anomaly and complained of diffuse myalgia and fatigue $^{25}$. More recently FM has been associated with increases in the periodic nonREM EEG sleep known as the cyclic alternating pattern $(\mathrm{CAP})^{26,27}$. CAP is characterized by sequences of transient EEG changes in nonREM sleep that occur distinctively from the background EEG activities. Samples of characteristic EEG tracings for Stage 2 nonREM sleep including normal, $\alpha$-EEG non-CAP, and CAP are shown in Figure 1. In FM, subtypes $\mathrm{CAP}_{\mathrm{A} 2}$ and $\mathrm{CAP}_{\mathrm{A} 3}$ are increased; these are indices of poor sleep quality or sleep instability ${ }^{26}$. In addition, elevated $\mathrm{CAP}_{\mathrm{A} 2}$ and $\mathrm{CAP}_{\mathrm{A} 3}$ in $\mathrm{FM}$ have been correlated with other measurements of arousal during sleep ${ }^{26}$. To the extent that nonrestorative sleep may exacerbate FM symptoms, treatments that improve sleep quality may improve daytime symptoms of FM.

Our study was designed to investigate the effects of bedtime administration of VLD CBP $(\leq 4 \mathrm{mg} /$ day $)$ in subjects with FM and nonrestorative sleep. It was also designed to identify measurements that may be useful markers of drug effects.

\section{MATERIALS AND METHODS}

Study overview. This was a randomized, double-blind, placebo-controlled, dose-escalating, parallel-design study in patients with FM and disrupted sleep conducted at 2 Canadian sites. Following a prestudy screening period of up to 21 days, patients were randomly assigned to receive either VLD CBP or placebo, in a 1:1 ratio, once daily for 8 weeks, to be taken between dinner and bedtime. The dosage was $1 \mathrm{mg}$ for the first 7 days, after which, if clinically indicated and according to tolerability, the daily dose could be increased up to $4 \mathrm{mg}$. The dose could be reduced at the discretion of the investigator. Randomized patients were seen by the study physician(s) every 1 or 2 weeks for 8 weeks to evaluate therapeutic benefit, safety, and tolerability of study drug, with a final visit 4 to 10 days after the last on-treatment visit. For patients who discontinued, the efficacy and safety determinations designated for Day 56 were obtained on the last day the patient took study medication or as soon as possible thereafter (within 3 days for efficacy). The protocol and informed consent forms were reviewed and approved by the ethics review board for each study site. Patients were enrolled in 2 Canadian centers, in Toronto, Ontario, and Calgary, Alberta.

Entry criteria. Male and female patients were eligible for inclusion if they were 18 to 65 years of age (inclusive), had documented FM and sleep disturbance, met the American College of Rheumatology (ACR) 2001 criteria for $\mathrm{FM}^{28}$, reported nonrestful sleep more nights than not for at least 3 months before the start of double-blind treatment, demonstrated the $\alpha$-nonREM EEG sleep anomaly at screening, and provided signed informed consent. Patients were excluded who had inflammatory rheumat-

Personal non-commercial use only. The Journal of Rheumatology Copyright (C) 2011. All rights reserved. 


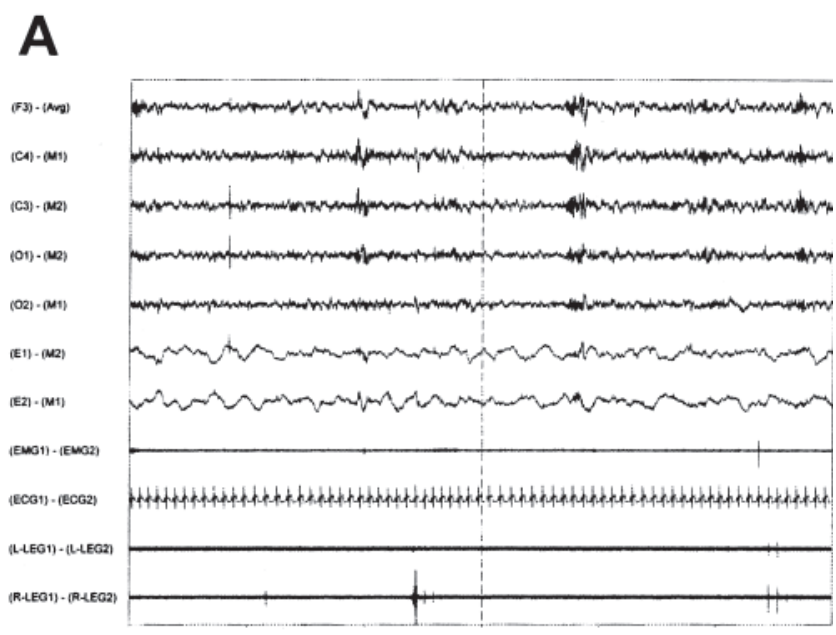

B

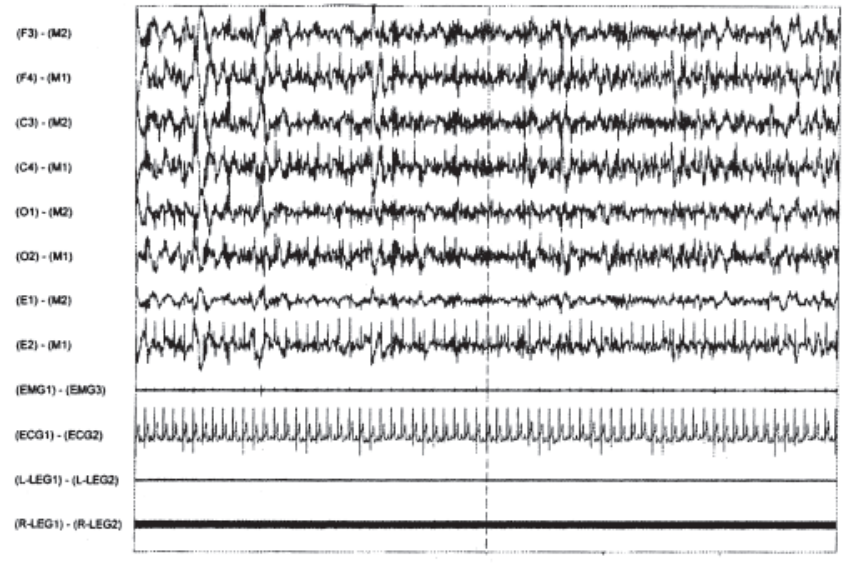

C

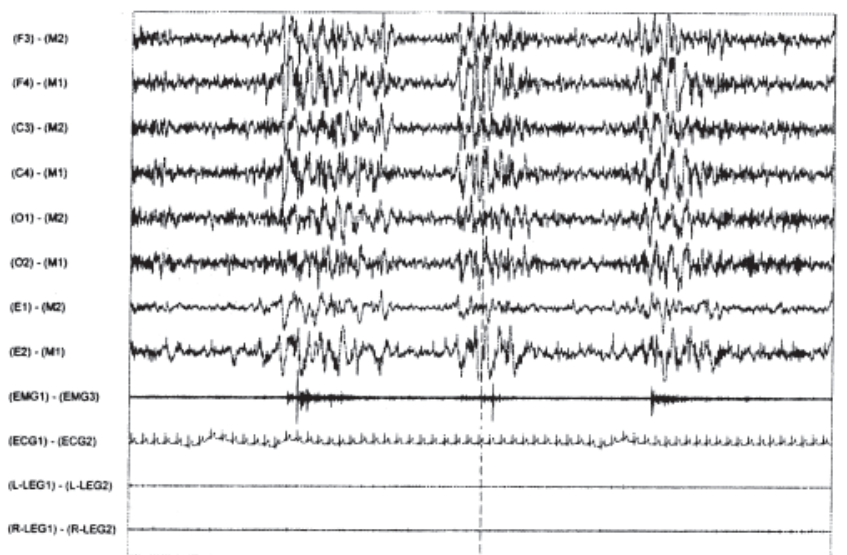

Figure 1. Examples of 60-second Stage 2 nonREM sleep EEG and electromyography (EMG) tracing. A. Normal; B. $\alpha$-EEG sleep; C. Cyclic alternating pattern (CAP) sleep EEG subtype A3 with increased submental EMG.

ic disease or a primary psychiatric disorder, were using psychopharmacologic drugs or nonsteroidal antiinflammatory drugs (NSAID), had a histo- ry or presence of sleep apnea or sleep-related periodic involuntary limb movements, or had used CBP within 3 months prior to the study. While patients had a range of prior treatments for FM, the study was conducted prior to the approval of pregabalin, duloxetine, or milnacipran.

Prior medications or treatments that were exclusion criteria included use of (1) electroconvulsive therapy within 3 months (or residual cognitive effects); (2) fluoxetine within 5 weeks; (3) any investigational drug, antipsychotic drug, or steroid (including topical steroids) within 1 month; (4) any antidepressant (including monoamine oxidase inhibitors), anxiolytic, sedative-hypnotic, anticholinergic, muscle relaxant, lithium, or any other psychopharmacologic drug within 2 weeks of the start of double-blind treatment; (5) any nonpsychopharmacologic drug within 2 weeks of the start of the double-blind treatment period unless a stable dose of the drug had been maintained for at least 1 month ( 3 months for thyroid or hormonal medications) before the start of the double-blind treatment period; and (6) any capsaicin-containing cream, NSAID, or salicylate within 2 weeks of the start of double-blind treatment.

Treatments permitted during the trial included psychotherapy, if well established before the study; acetaminophen for headache; and nonpsychopharmacologic drugs if the patient had been receiving a stable dose of the drug for at least 1 month before the start of double-blind treatment (at least 3 months before double-blind treatment for thyroid medications and hormonal medications).

EEG and other variables assessed during sleep. Patients were evaluated in the sleep laboratory on 5 nights: at screening, baseline, and 3 on-treatment weeks, usually Weeks 2, 4, and 8. Overnight sleep EEG recording, commonly referred to as polysomnogram recordings (PSG), measured total sleep time, total awake time, sleep efficiency, percentage of time spent in each sleep stage, sleep stage changes, $\alpha$-EEG sleep ratings, and movement arousals. Sleep records were scored blindly in 30-second epochs according to standard criteria. Scoring was centralized at 1 site (Dr. H. Moldofsky, Toronto). The PSG was performed and analyzed according to the Rechtschaffen and Kales criteria ${ }^{29}$ before the current American Academy of Sleep Medicine rules were introduced.

To be included for study, patients had to exhibit the $\alpha$-nonREM sleep anomaly at screening and baseline. The $\alpha$-nonREM sleep activity was rated in Stages 2, 3, and 4. Total activity (all 3 stages), Stage 2 activity, and Stage 3-4 activity were each scored on a 1-5 scale, according to the percentage of sleep epochs in those sleep stages that contained an $\alpha$-EEG rhythm ${ }^{30}$. A patient was determined to have the $\alpha$-nonREM sleep anomaly at screening if $>40 \%$ of sleep epochs contained $\alpha$-EEG activity (a rating of 3 or higher) or at least 10 episodes of periodic $\mathrm{k}-\alpha . \mathrm{K}-\alpha$ episodes were defined as periodic (every 20 to $40 \mathrm{~s}$ ) k-complexes immediately followed by $\alpha$-EEG activity 0.5 to $5 \mathrm{~s}$ in duration. K- $\alpha$ episodes were scored during Stage 2, 3, and 4 sleep ${ }^{24,30}$.

Cyclic alternating pattern (CAP). Subsequent to enrollment and completion, EEG sleep studies in patients with FM were reported that identified increases in the periodic sleep EEG arousal disorder known as CAP in nonREM sleep, a measure of sleep instability related to the symptoms of $\mathrm{FM}^{26}$. Analysis of nocturnal sleep EEG CAP was determined by employing a computerized automatic detection analysis using the Embla PSG system ${ }^{27,31}$ that provides the frequency of total CAP and subtypes of $\mathrm{CAP}_{\mathrm{A} 1}$, $\mathrm{CAP}_{\mathrm{A} 2}$, and $\mathrm{CAP}_{\mathrm{A} 3}{ }^{32,33}$. CAP was scored during Stage 2, 3, and 4 sleep. $\mathrm{K}-\alpha$ episodes are a variety of CAP.

Efficacy variables. Pain, tenderness, fatigue, and mood are symptoms of FM consistent with the current Outcome Measures in Rheumatology Clinical Trials (OMERACT) guidelines ${ }^{1,34}$.

Safety and tolerability assessments. Adverse events (AE) were recorded at all study visits or as they occurred. Blood chemistry tests (including thyroid-stimulating hormone at screening only), hematology tests, and urinalysis were performed at screening and on Days -1 and 56. A urine drug screen was performed at screening. Serum ß-human chorionic gonadotropin measurement was performed on women of childbearing potential at screening and on Days -1 and 56 . Laboratory tests with values 
that became clinically significantly abnormal after drug administration were repeated until the values returned to normal or the etiology was identified and the sponsor notified. Laboratory determinations were performed by a central laboratory, MDS Pharma Services, Toronto.

Sitting pulse and blood pressure measurements were taken at all visits. Standard 12-lead electrocardiography (ECG) measures were performed at screening and on Days -1 and 56. A comprehensive physical examination, including oral temperature, was performed at screening and on Day 56. Height was measured at screening and weight at all visits.

AE were coded using COSTART. Treatment-emergent AE (TEAE) were summarized by number (\%) of patients according to preferred term and system/organ class, and the treatment arms were compared in terms of incidence of AE reported by $\geq 10 \%$ of patients in either arm using Fisher's exact test. AE and serious adverse events (SAE) were summarized by severity and relationship to study treatment.

Laboratory data were summarized, and mean change was presented for each numeric variable. Laboratory data were classified as low, normal, or high and out-of-range values were flagged. Within-group values for numeric variables were summarized. Scatterplots were generated for selected laboratory tests. The treatment arms were compared with respect to mean change using the 2-sample $t$ test. Vital signs and weight were summarized for each study visit, and the groups were compared with respect to mean change using the 2-sample t test. Physical examination data were listed, and any new physical findings were summarized. Selected ECG variables were summarized at baseline and at the end of treatment, and treatments were compared using a 2-sample $t$ test for actual value and change from baseline. The proportions of patients with a normal ECG were compared at baseline and end of treatment by Fisher's exact test.

Assessment of treatment compliance. A record of all medication dispensed and returned during the study was maintained by the investigators. Treatment compliance was assessed by (1) counting each patient's remaining capsules at each study visit, (2) subtracting this number from the amount originally in each bottle (yielding the number of capsules taken), and (3) dividing this number into the number of capsules that should have been taken, per protocol, during the period between study visits.

Statistical analyses. Analyses for musculoskeletal pain, fatigue, tenderness,
HAD total score, HAD anxiety subscale, HAD depression subscale, sleep $\alpha$-EEG rating, sleep time, percentage time spent in each sleep stage, percentage REM sleep, latency to Stage 2, REM latency, and sleep efficiency were performed using a paired $t$ test for within-group change with a 2-sided $\mathrm{p}$ value. In addition, the VLD CBP and placebo groups were compared using change from baseline at Week 8 using a 2-sample $t$ test with a 2-sided p value. Clinical global impression of change (CGIC) and patient global impression of change (PGIC) scores (each question, e.g., fatigue, sleep disturbance, musculoskeletal pain, and morning stiffness and aching) were analyzed with the Cochran-Mantel-Haenszel test on row means, using modified ridit scores. Since one of the goals of this Phase 2 study was to elicit signals of treatment effect over the many variables studied, no adjustment of $\mathrm{p}$ values was made for multiplicity.

\section{RESULTS}

Patient disposition. A total of 36 patients with FM and nonrestorative sleep were enrolled and treated (VLD CBP, $\mathrm{n}=$ 18 , and placebo, $\mathrm{n}=18$ ). Thirty-seven patients satisfied the screening criteria, but prior to treatment 1 patient was discovered to have been randomized in error upon examination of her screening ECG results and was never dosed and was consequently omitted from the intention-to-treat (ITT) and safety populations (Figure 2).

Twenty-nine patients completed the study. Similar percentages of VLD CBP and placebo-treated subjects completed the study (89\% of the VLD CBP group, $68 \%$ of the placebo group). One placebo-treated patient discontinued because of an AE. Three placebo patients were discontinued per protocol due to normalization of an $\alpha$-nonREM sleep EEG abnormality between screening and baseline ( $\alpha$ score $<3$ ). One placebo patient and 2 VLD CBP patients were asked to return after 1 week instead of 2 weeks following Visits 6 and 7 and thus received only 6 weeks of therapy.

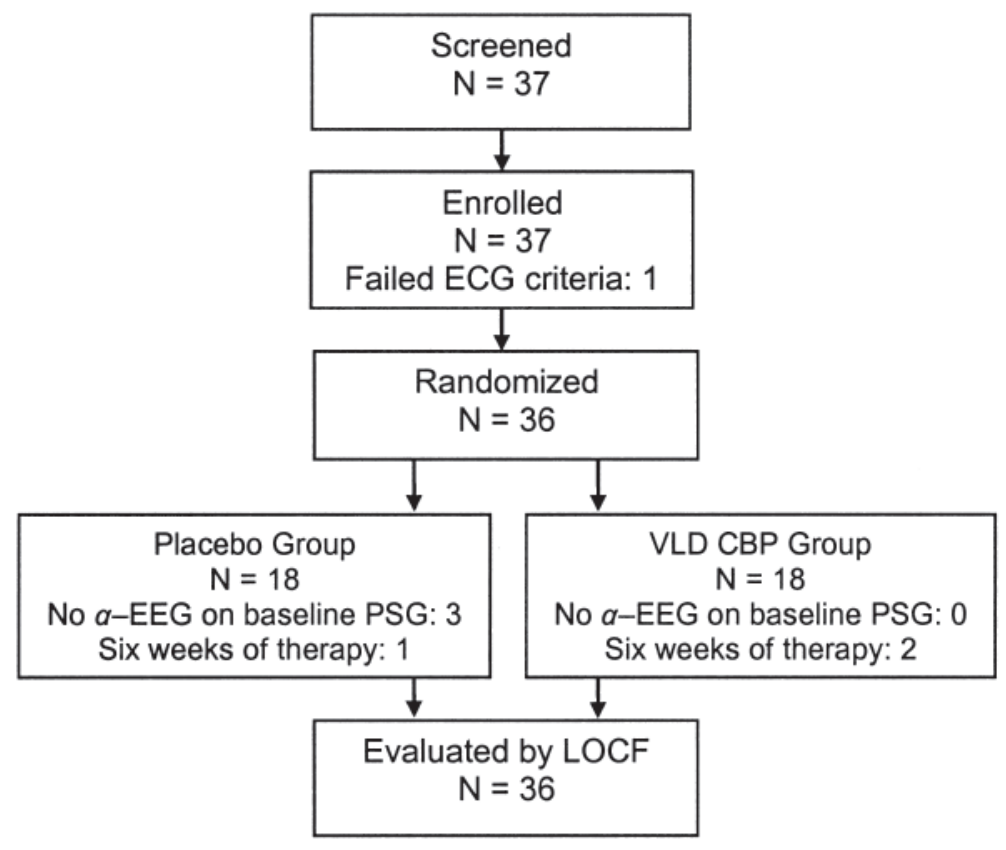

Figure 2. The progress of the study. VLD CBP: very low dose cyclobenzaprine; PSG: polysomnogram; LOCF: last observation carried forward. 
Table 1. Demographic and other baseline characteristics.

\begin{tabular}{lcc}
\hline Characteristic & $\begin{array}{c}\text { VLD CBP, } \\
\mathrm{N}=18\end{array}$ & $\begin{array}{c}\text { Placebo, } \\
\mathrm{N}=18\end{array}$ \\
\hline $\begin{array}{l}\text { Sex, n (\%) } \\
\text { Male }\end{array}$ & 0 & $1(6)$ \\
$\quad \begin{array}{l}\text { Female } \\
\begin{array}{l}\text { Age, yrs, mean (SD), } \\
\text { range }\end{array}\end{array}$ & $18(100)$ & $17(94)$ \\
$\begin{array}{l}\text { Race (white, non-Hispanic) } \\
(\%)\end{array}$ & $45.9(11.4), 26-62$ & $39.3(9.3), 23-56$ \\
$\begin{array}{l}\text { Weight, kg, mean (SD), } \\
\text { range }\end{array}$ & $18(100)$ & $18(100)$ \\
$\begin{array}{l}\text { Height, cm, mean (SD), } \\
\text { range }\end{array}$ & $68.1(10.1), 53-86$ & $73.8(16.3), 53-108$ \\
& $162.3(8.8), 148-178$ & $165.9(5.6), 160-178$ \\
\hline
\end{tabular}

Three patients considered completers had final efficacy evaluations at Week 7 and 5 patients had final efficacy evaluations after but not during Week 8 . The average time in the study was 54 days.

Patient characteristics. Table 1 shows the anthropometric data for patients with FM. There were no meaningful differences between the 2 treatment groups in demographic or other baseline data. All patients were white and all patients but 1 were women, with a mean age of 43 years; $50 \%$ of patients in each group had had FM for more than 72 months. The 2 groups were also similar in terms of FM history. The time elapsed since diagnosis of FM was similar in the 2 groups, and all but 1 of the patients had received prior therapies for FM.

Dose titration of $C B P$. CBP was formulated as $1 \mathrm{mg}$ capsules, and placebo capsules contained no CBP. Investigators were allowed to adjust dosage throughout the study as tolerability allowed. Daily dose ranged from 2 to $4 \mathrm{mg}$ in the VLD CBP group at Week 8, with a group mean of $3.1 \mathrm{mg}$. Placebo capsules were titrated to a dose corresponding to $2.1 \mathrm{mg}$.

Tolerability. VLD CBP was well tolerated, with only 1 severe $\mathrm{AE}$ (headache), compared to 5 severe $\mathrm{AE}$ in the placebo group. One patient in the placebo group discontinued prematurely because of nonsymptomatic arrhythmias. There were no serious AE in this trial. No new or unexpected $\mathrm{AE}$ emerged during treatment, nor were there any clinically significant trends in laboratory test results, vital signs, ECG results, or physical examination findings. The most common TEAE, which occurred in $>10 \%$ of subjects and in $>5 \%$ of VLD CBP-treated subjects, are shown in Table 2. Overall, the types of TEAE observed were relatively consistent with those reported in the Flexeril product label.

VLD CBP effects on FM symptoms. Eighteen VLD CBP-treated and 18 placebo-treated subjects were evaluated using last observation carried forward (LOCF) and compared using a paired $t$ test for within-group change with a 2 -sided $\mathrm{p}$ value (Table 3 ). In addition, the VLD CBP and
Table 2. Most common (> 10\%) treatment-emergent adverse events.

\begin{tabular}{lcc}
\hline Adverse Event & $\begin{array}{c}\text { VLD CBP } \\
(\mathrm{N}=18), \mathrm{n}(\%)\end{array}$ & $\begin{array}{c}\text { Placebo } \\
(\mathrm{N}=18), \mathrm{n}(\%)\end{array}$ \\
\hline Any adverse event & $15(83)$ & $15(83)$ \\
Headache & $7(39)$ & $3(17)$ \\
Dry mouth & $6(33)$ & $1(6)$ \\
Somnolence & $4(22)$ & $2(11)$ \\
Constipation & $3(17)$ & $1(6)$ \\
Dizziness & $3(17)$ & $1(6)$ \\
Nausea & $2(11)$ & $5(28)$ \\
Flu syndrome & $2(11)$ & $1(6)$ \\
Rhinitis & $2(11)$ & $1(6)$ \\
Pruritus & $2(11)$ & 0 \\
\hline
\end{tabular}

placebo groups were compared using change from baseline at Week 8 using a 2 -sample $t$ test with a 2 -sided $p$ value (Table 3).

Bedtime musculoskeletal pain and fatigue. The bedtime questionnaire recorded subjects' assessments of pain and fatigue about $24 \mathrm{~h}$ after ingestion of the VLD CBP or placebo. Musculoskeletal pain was rated on a 7-point scale of 0-6 (from "no discomfort" to "worst possible discomfort") at each of 10 specific body sites. Scores at these sites were then averaged to provide an assessment of overall musculoskeletal pain. For subjects who received VLD CBP, the mean musculoskeletal pain score changed from 2.3 at baseline to 1.7 at Week 8 , which was a decrease (or improvement) of $0.6(26.1 \%$; $=0.010)$. In contrast, placebo treatment did not result in statistically significant changes in musculoskeletal pain, which remained at an average score of 2.1 at baseline and at Week $8(0.0 \% ; \mathrm{p}=1.000)$. The mean change from baseline of the VLD CBP and placebo groups at Week 8 differed significantly and revealed that VLD CBP treatment significantly improved musculoskeletal pain $(\mathrm{p}=$ 0.044; Table 3).

Fatigue was rated on a 7 -point scale of 1 to 7 (where $1=$ "full of energy" and 7 = "totally physically exhausted"). For subjects who received VLD CBP, the mean fatigue score changed from 5.0 at baseline to 4.3 at Week 8 , which was a decrease (or improvement) of $0.7(14.0 \% ; \mathrm{p}=0.039)$. In contrast, placebo treatment did not result in statistically significant changes in fatigue, from 4.7 at baseline to 4.9 at Week 8, which was an increase of $0.2(4.3 \%$; $\mathrm{p}=0.647)$. However, the mean change from baseline of the VLD CBP and placebo groups at Week 8 did not differ significantly (Table 3).

Tenderness. In patients with FM, the application of pressure $\left(4 \mathrm{~kg} / \mathrm{cm}^{2}\right)$ to specific body regions $(9$ bilateral "tender points," 18 total "tender points") elicits a more painful reaction than normal; this may be assessed by using a dolorimeter to determine the specific amount of pressure (0-6 $\mathrm{kg} / \mathrm{cm}^{2}$ ) required to elicit pain at each of 6 tender points and totaling this score $\left(0-36 \mathrm{~kg} / \mathrm{cm}^{2}\right)$. For subjects who received VLD CBP, the dolorimetry score changed from $14.3 \mathrm{~kg} / \mathrm{cm}^{2}$ Personal non-commercial use only. The Journal of Rheumatology Copyright (c) 2011. All rights reserved. 
Table 3. Effect of very low dose cyclobenzaprine (VLD CBP) on FM symptoms.

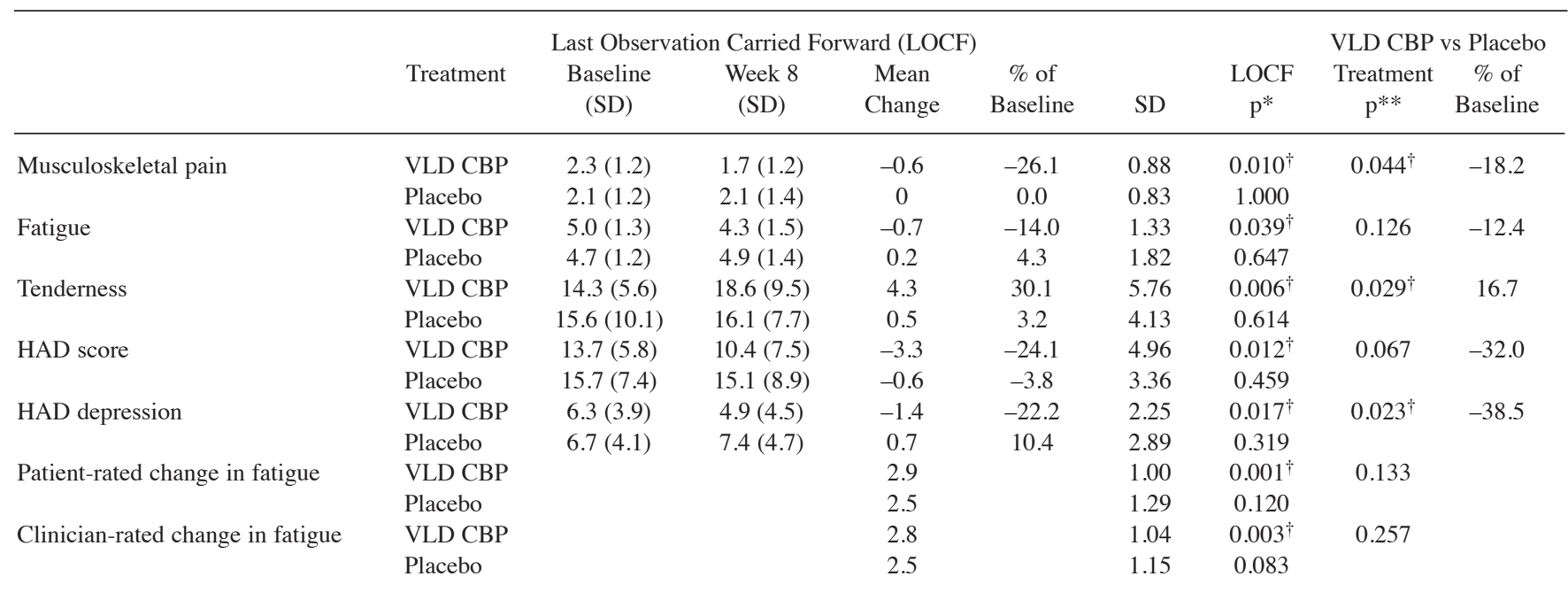

* Each $t$ test is used to test that within-group change from baseline is significant, i.e., different from 0. $\mathrm{p}$ value is 2-sided. **ANOVA p value comparing mean change from baseline between treatments. ${ }^{\dagger} \mathrm{p} \leq 0.05$. HAD: Hospital Anxiety and Depression Scale.

at baseline to $18.6 \mathrm{~kg} / \mathrm{cm}^{2}$ at Week 8 , which was an increase (or improvement) of $4.3 \mathrm{~kg} / \mathrm{cm}^{2}(30.1 \%$; $\mathrm{p}=0.006)$. In contrast, placebo treatment did not result in statistically significant changes in dolorimetry score, from $15.6 \mathrm{~kg} / \mathrm{cm}^{2}$ at baseline to $16.1 \mathrm{~kg} / \mathrm{cm}^{2}$ at Week 8 , a change of $0.5 \mathrm{~kg} / \mathrm{cm}^{2}$ $(3.2 \% ; \mathrm{p}=0.614)$. The mean change from baseline of the VLD CBP and placebo groups at Week 8 revealed that VLD CBP treatment improved the dolorimetry score significantly $(\mathrm{p}=0.029$; Table 3).

Hospital Anxiety and Depression Scale (HAD). The HAD is a widely used patient self-rated scale with 14 questions (7 anxiety and 7 depression questions) ranging from 0 to 42 . For subjects who received VLD CBP, the HAD score changed from 13.7 at baseline to 10.4 at Week 8, which was a decrease (or improvement) of $3.3(24.1 \% ; \mathrm{p}=0.012)$. In contrast, placebo treatment did not result in statistically significant changes in HAD scale, 15.7 at baseline and 15.1 at Week 8 (3.8\%; $p=0.459)$. Comparison of the change from baseline between the VLD CBP and placebo groups at Week 8 did not reveal a significant effect of VLD CBP treatment on the HAD scale (Table 3 ).

The HAD depression subscale score (range 0-21) was also analyzed. For subjects who received VLD CBP, the HAD depression subscale changed from 6.3 at baseline to 4.9 at Week 8, a decrease (or improvement) of 1.4 (22.2\%; $\mathrm{p}=0.017)$. In contrast, placebo treatment did not result in statistically significant changes in intragroup HAD depression subscale scores, from 6.7 at baseline to 7.4 at Week 8, an increase of $0.7(10.4 \% ; p=0.319)$. Comparison of the change from baseline between the VLD CBP and placebo groups at Week 8 revealed that VLD CBP treatment was associated with a significant improvement in the HAD depression subscale score $(p=0.023$; Table 3$)$.
Clinician-rated and patient-rated improvement scales for fatigue. At each post-baseline visit, the CGIC and PGIC scores were rated separately by the clinician and by the patient, respectively. Fatigue was evaluated using a scale of 5 ("worse") to 1 ("marked improvement"). VLD CBP treatment was associated with a statistically significant improvement in patient-rated and clinician-rated change in fatigue ( $p=0.001$ and $p=0.004$, respectively). In contrast, placebo treatment did not result in statistically significant changes in any of these measures. Relative to placebo, VLD CBP treatment did not significantly improve patient-rated or clinician-rated improvement in fatigue $(\mathrm{p}=0.133, \mathrm{p}=0.237$, respectively; Table 3).

Effect of VLD CBP on macrostructure of sleep EEG. VLD CBP treatment at bedtime was studied for its effects on sleep EEG. PSG was performed at prestudy screening, at baseline, and typically at Weeks 2, 4, and 8. In the VLD CBP-treated group from baseline to Week 8 , total time awake decreased from $1.3 \mathrm{~h}$ to $0.8 \mathrm{~h}$, which was an improvement of $38.5 \%$ $(\mathrm{p}=0.011)$, while total sleep time increased $5.7 \mathrm{~h}$ to $6.4 \mathrm{~h}$, an improvement of $12.3 \%(\mathrm{p}=0.005)$ and sleep efficiency increased $73.6 \%$ to $85.1 \%$, an improvement of $15.6 \%$ ( $\mathrm{p}=$ $0.023)$. In contrast, placebo treatment did not result in statistically significant changes in any of these measures. Compared to placebo, VLD CBP treatment did not significantly change total time awake, total sleep time, or sleep efficiency (Table 4).

Within the VLD CBP group from baseline to Week 8, VLD CBP treatment did not significantly change the percentages of Stage 1, 2, 3, or 4 or REM sleep (Table 4). However, in a change from baseline analysis, compared to placebo, VLD CBP was associated with an $11.1 \%$ increase in Stage 2 sleep ( $56.5 \%$ vs $50.6 \%$ for placebo; $p=0.021$ ), a

Personal non-commercial use only. The Journal of Rheumatology Copyright @ 2011 . All rights reserved. 
Table 4. Effect of very low dose cyclobenzaprine (VLD CBP) on sleep EEG.

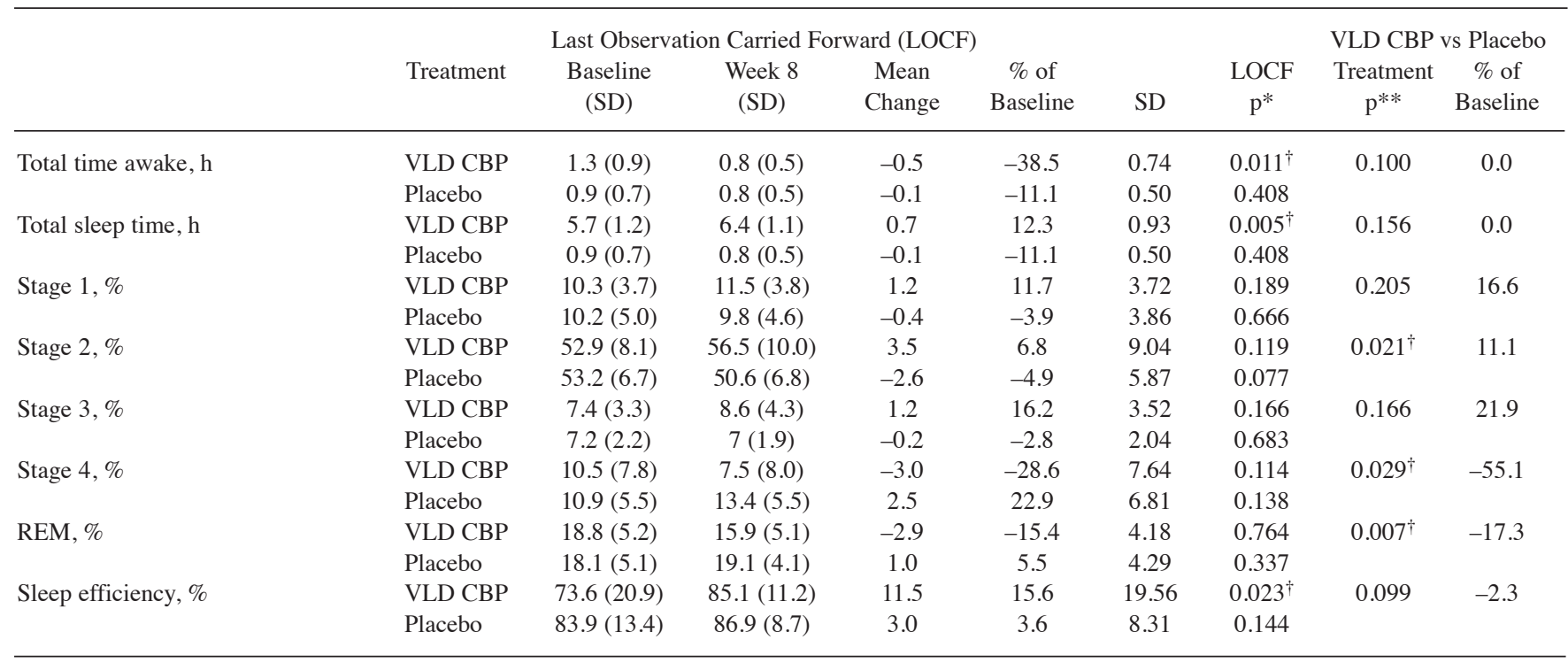

* Each $\mathrm{t}$ test is used to test that within-group change from baseline is significant, i.e., different from 0. $\mathrm{p}$ value is 2 -sided. **ANOVA p value comparing mean change from baseline between treatments. ${ }^{\dagger} \mathrm{p} \leq 0.05$.

$55.1 \%$ decrease in Stage 4 sleep (7.5\% vs $13.4 \%$ for placebo; $\mathrm{p}=0.029)$, and a $17.3 \%$ decrease in REM sleep (15.9\% vs $19.1 \%$ for placebo; $\mathrm{p}=0.007$; Table 4 ).

$V L D C B P$ effects on $C A P_{A 2}+C A P_{A 3}$. Subsequent to enrollment and completion, EEG sleep studies in FM patients were reported that identified increases in the periodic sleep EEG arousal disorder known as CAP in nonREM sleep ${ }^{26,27}$. Therefore, an analysis of sleep EEG CAP was performed that measured subtypes $\mathrm{CAP}_{\mathrm{A} 1}, \mathrm{CAP}_{\mathrm{A} 2}$, and $\mathrm{CAP}_{\mathrm{A} 3}$ and Total CAP (or $\mathrm{CAP}_{\mathrm{A} 1}+\mathrm{CAP}_{\mathrm{A} 2}+\mathrm{CAP}_{\mathrm{A} 3}$ ). Subtype $\mathrm{CAP}_{\mathrm{A} 1}$ is associated with sleep maintenance or least sleep instability, and subtypes $\mathrm{CAP}_{\mathrm{A} 2}$ and $\mathrm{CAP}_{\mathrm{A} 3}$ are associated with moderate to prominent increases in sleep instability.

Because $\mathrm{CAP}_{\mathrm{A} 2}$ and $\mathrm{CAP}_{\mathrm{A} 3}$ are most closely associated with sleep instability ${ }^{26,27}$, the sum of $\mathrm{CAP}_{\mathrm{A} 2}+\mathrm{CAP}_{\mathrm{A} 3}$ rates $\left(\mathrm{CAP}_{\mathrm{A} 2+\mathrm{A} 3}\right)$ was used as an indicator of disordered sleep. $\mathrm{CAP}_{\mathrm{A} 2+\mathrm{A} 3}$ was normalized $\left(\mathrm{CAP}_{\mathrm{A} 2+\mathrm{A} 3 \text { (Norm) }}\right)$ by dividing $\mathrm{CAP}_{\mathrm{A} 2+\mathrm{A} 3}$ by the total $\mathrm{CAP}$ rate $\left(\mathrm{CAP}_{\text {total }}=\mathrm{CAP}_{\mathrm{A} 1}+\right.$ $\mathrm{CAP}_{\mathrm{A} 2}+\mathrm{CAP}_{\mathrm{A} 3}$ rates $=\mathrm{CAP}_{\mathrm{A} 1+\mathrm{A} 2+\mathrm{A} 3}$ ) and expressed as a percentage. Therefore, $\mathrm{CAP}_{\mathrm{A} 2+\mathrm{A} 3(\mathrm{Norm})}=100 \times$ $\mathrm{CAP}_{\mathrm{A} 2+\mathrm{A} 3} / \mathrm{CAP}_{\mathrm{A} 1+\mathrm{A} 2+\mathrm{A} 3}$ and this yields the percentage of total CAP that is associated with sleep instability.

To determine whether patients experienced nights with a potential CAP response to treatment, it was necessary to determine an empirical threshold below which $\mathrm{CAP}_{\mathrm{A} 2+\mathrm{A} 3 \text { (Norm) }}$ values reflect a night of relatively stable sleep for this population. To determine a threshold for $\mathrm{CAP}_{\mathrm{A} 2+\mathrm{A} 3(\mathrm{Norm})}$ that could be informative for a potential treatment response, the study CAP data were then evaluated by considering a range of cutoff values for $\mathrm{CAP}_{\mathrm{A} 2+\mathrm{A} 3(\mathrm{Norm})}$ from $\leq 10 \%$ to $\leq 50 \%$. Testing various $\mathrm{CAP}_{\mathrm{A} 2+\mathrm{A} 3 \text { (Norm) }}$ values revealed that defining a threshold for response
$\mathrm{CAP}_{\mathrm{A} 2+\mathrm{A} 3 \text { (Norm) }} \leq 33 \%$ distinguished VLD CBP-treated subjects from placebo-treated subjects (Table 5), at which threshold the percentage of patients with increased nights of CAP response while on treatment (ITT, LOCF) was $72 \%$ with VLD CBP compared to $33 \%$ with placebo $(p=0.019)$. The finding that $\mathrm{CAP}_{\mathrm{A} 2+\mathrm{A} 3 \text { (Norm) }} \leq 33 \%$ may be a relatively healthy $\mathrm{CAP}_{\mathrm{A} 2+\mathrm{A} 3 \text { (Norm) }}$ value for patients with FM is consistent with our analysis of previously published normative data ${ }^{26}$.

Correlation of $C A P_{A 2+A 3(\text { Norm })}$ with FM symptoms. To evaluate whether increased nights with $\mathrm{CAP}_{\mathrm{A} 2+\mathrm{A} 3 \text { (Norm) }} \leq 33 \%$ was correlated with clinical improvement measures in pain, fatigue, tenderness, HAD, and HAD depression over the course of the study (LOCF Week 8), Spearman's rank correlation was investigated separately for each treatment. Data were coded such that improvements were positive. Within the VLD CBP-treated patients, increased nights with $\mathrm{CAP}_{\mathrm{A} 2+\mathrm{A} 3 \text { (Norm) }} \leq 33 \%$ was found to correlate positively to decreases in fatigue ( $r h o=0.62, p=0.006)$, HAD total score (rho $=0.505, \mathrm{p}=0.033), \mathrm{HAD}$ depression subscale (rho $=$ $0.556, \mathrm{p}=0.017$ ), patient-rated fatigue (rho $=0.614, \mathrm{p}=$ 0.007 ), and clinician-rated fatigue ( $r h o=0.582, p=0.0112$; Table 6). In contrast, improved CAP response was not correlated with either musculoskeletal pain or dolorimetry results (Table 6). Within the placebo-treated subjects, none of these FM symptoms or sleep EEG measures was significantly correlated to increased number of nights with $\mathrm{CAP}_{\mathrm{A} 2+\mathrm{A} 3 \text { (Norm) }} \leq 33 \%$ (Table 6). In the placebo group, increased nights of CAP response correlated with measures of improved sleep, that is, a positive correlation with sleep efficiency and a negative correlation with total time awake. Together, these findings suggest that nights with $\mathrm{CAP}_{\mathrm{A} 2+\mathrm{A} 3 \text { (Norm) }} \leq 33 \%$ may reflect relatively healthy or Personal non-commercial use only. The Journal of Rheumatology Copyright $@$ C 2011. All rights reserved. 
Table 5. Effect of varying $\mathrm{CAP}_{\mathrm{A} 2+\mathrm{A} 3 \text { (Norm) }}$ threshold (from $\leq 10 \%$ to $\leq$ $50 \%$ ) on percentage of subjects improving CAP response by $\geq 1$ night.

\begin{tabular}{|c|c|c|c|}
\hline \multirow{2}{*}{$\begin{array}{c}\mathrm{CAP}_{\mathrm{A} 2+\mathrm{A} 3 \text { (Norm) }} \\
\text { Response } \\
\text { Threshold, \% }\end{array}$} & \multicolumn{2}{|c|}{$\begin{array}{c}\text { Subjects } \\
\text { Improving } \geq 1 \text { Night }\end{array}$} & \multirow[b]{2}{*}{$\mathrm{p}$} \\
\hline & VLD CBP, \% & Placebo, $\%$ & \\
\hline 10 & 56 & 28 & 0.0910 \\
\hline 20 & 50 & 17 & $0.0339^{\dagger}$ \\
\hline 25 & 56 & 28 & 0.0910 \\
\hline 30 & 72 & 33 & $0.0194^{\dagger}$ \\
\hline 33 & 72 & 33 & $0.0194^{\dagger}$ \\
\hline 40 & 78 & 61 & 0.2777 \\
\hline 45 & 89 & 67 & 0.0880 \\
\hline 50 & 89 & 67 & 0.1088 \\
\hline
\end{tabular}

${ }^{\dagger} \mathrm{p}<0.05$. CAP: cyclic alternating pattern.

Table 6. Correlation of increased nights of $\mathrm{CAP}_{\mathrm{A} 2+\mathrm{A} 3 \text { (Norm) }} \leq 33 \%$ with VLD CBP improvements on FM symptoms and sleep EEG measures.

\begin{tabular}{|c|c|c|c|c|}
\hline \multirow[b]{2}{*}{ Variable } & \multicolumn{2}{|c|}{$\begin{array}{c}\text { VLD CBP } \\
\text { CAP }_{\mathrm{A} 2+\mathrm{A} 3 \text { (Norm) }} \\
\text { Correlation }\end{array}$} & \multicolumn{2}{|c|}{$\begin{array}{c}\text { Placebo } \\
\mathrm{CAP}_{\mathrm{A} 2+\mathrm{A} 3(\mathrm{Norm})} \\
\text { Correlation }\end{array}$} \\
\hline & $\mathrm{r}$ & $\mathrm{p}$ & $\mathrm{r}$ & $\mathrm{p}$ \\
\hline Musculoskeletal pain & 0.036 & 0.888 & -0.091 & 0.719 \\
\hline Fatigue & 0.617 & $0.006^{\dagger}$ & -0.466 & 0.051 \\
\hline Dolorimetry & 0.036 & 0.888 & 0.341 & 0.166 \\
\hline HAD score & 0.505 & $0.033^{\dagger}$ & -0.196 & 0.435 \\
\hline HAD depression subscore & 0.556 & $0.017^{\dagger}$ & -0.276 & 0.267 \\
\hline Patient-rated change in fatigue & 0.614 & $0.007^{\dagger}$ & -0.073 & 0.773 \\
\hline Clinician-rated change in fatigue & 0.582 & $0.011^{\dagger}$ & 0.288 & 0.247 \\
\hline Total time awake, $\mathrm{h}$ & 0.072 & 0.777 & -0.551 & $0.018^{\dagger}$ \\
\hline Total sleep time, $\mathrm{h}$ & 0.228 & 0.364 & 0.552 & $0.018^{\dagger}$ \\
\hline Stage $1, \%$ & -0.036 & 0.413 & 0.206 & 0.413 \\
\hline Stage $2, \%$ & -0.012 & 0.963 & -0.525 & $0.025^{\dagger}$ \\
\hline Stage $3, \%$ & 0.179 & 0.477 & 0.160 & 0.526 \\
\hline Stage $4, \%$ & 0.072 & 0.777 & 0.161 & 0.524 \\
\hline REM, \% & -0.096 & 0.706 & 0.480 & $0.044^{\dagger}$ \\
\hline Sleep efficiency, $\%$ & -0.179 & 0.477 & 0.662 & $0.003^{\dagger}$ \\
\hline
\end{tabular}

${ }^{\dagger} \mathrm{p} \leq 0.05$. CAP: cyclic alternating pattern; HAD: Hospital Anxiety and Depression Scale.

restorative sleep for patients with FM as symptoms vary naturally over the course of the condition, as well as providing a potential biomarker for treatment effects.

\section{DISCUSSION}

Our study was designed to investigate the effects of bedtime dosing of VLD CBP ( $\leq 4 \mathrm{mg} /$ day) in subjects with FM and disrupted sleep. It was also designed to identify variables that might be useful markers of drug effects. The rationale for the study was that bedtime administration of VLD CBP would have a more acceptable side effect profile than higher doses administered during the day ${ }^{2,3,4,5,6,7,8}$, and yet might show effects on FM symptoms.

VLD CBP was well tolerated, with no serious AE or dis- continuations because of AE. The safety profile of VLD CBP compared favorably to that of placebo and the types of TEAE observed in this study were relatively consistent with those reported in the Flexeril (immediate-release CBP) product label. In particular, the prevalence of daytime drowsiness was lower with evening bedtime VLD CBP, at $22 \%$ of patients, vs $34 \%$ reported in a study in FM patients with higher daytime dosages (up to $40 \mathrm{mg}$ ) of $\mathrm{CBP}^{2}$.

Our study showed bedtime treatment with VLD CBP provided benefit to FM patients by improving pain, tenderness, fatigue, mood, and sleep quality. Both the $\mathrm{ACR}^{28}$ and OMERACT ${ }^{1,34}$ recognize pain as the key feature and pain sensitivity or tenderness as another important feature. Bedtime treatment with VLD CBP over 8 weeks improved musculoskeletal pain recorded about $24 \mathrm{~h}$ after dosing. Bedtime VLD CBP also improved tenderness measured by pressure dolorimetry. Fatigue and depressive symptoms are recognized as special treatment-outcome features of FM by OMERACT. Bedtime VLD CBP improved fatigue recorded about $24 \mathrm{~h}$ after dosing and also improved fatigue measured by self-rated and clinician-rated change over the course of the study. Bedtime VLD CBP improved mood measured by the HAD scale and the HAD depression subscale. Subjects who received placebo showed no significant improvement in any of these measures. Together, these findings show that bedtime treatment with VLD CBP provided benefit to patients with FM by improving symptoms of pain, tenderness, fatigue, and depressed mood.

Another goal of FM therapies, according to OMERACT consensus, is to improve sleep quality, because unrefreshing sleep is a key feature of FM and also because treatments that improve sleep quality are hypothesized to improve waking symptoms of FM. Traditional physiological measures of sleep quality showed bedtime VLD CBP treatment improved sleep efficiency by decreasing total time awake after sleep onset and increasing total sleep time. Placebo treatment did not significantly change these sleep variables. However, compared to placebo, VLD CBP treatment did not significantly change total time awake, total sleep time, and sleep efficiency, which may relate to the number of patients studied. VLD CBP treatment decreased Stage 4 EEG nonREM sleep and decreased REM, which is not consistent with either increased Stage 4 or REM serving as surrogates for refreshing sleep.

Unrefreshing sleep in FM may relate to an arousal disturbance during EEG sleep, termed the $\alpha$-EEG nonREM anomaly ${ }^{24}$. The arousal disturbance in FM sleep has been analyzed by periodic sleep EEG features, described as periodic k- $\alpha$ and periodic bursts of polyphasic sleep EEG in nonREM sleep. Subsequently these periodic sleep EEG phenomena were classified as aspects of $\mathrm{CAP}^{35}$. Where these periodic EEG activities show slow waves they are known as $\mathrm{CAP}_{\mathrm{A} 1}$, which is a feature of stable EEG nonREM sleep. On the other hand, $\mathrm{CAP}_{\mathrm{A} 2}$ and $\mathrm{CAP}_{\mathrm{A} 3}$ in nonREM sleep are

Personal non-commercial use only. The Journal of Rheumatology Copyright @ ( 2011. All rights reserved. 
considered features of unstable nonREM sleep, with $\mathrm{CAP}_{\mathrm{A} 3}$ showing greater physiological changes with associated increased neuromotor and sympathetic autonomic activities $^{26}$. While observer-rated measures of EEG sleep are subject to interobserver or interlaboratory variability, the computerized Embla algorithm provides a more objective method of quantification. EEG sleep studies show patients with $\mathrm{FM}$ have increases in $\mathrm{CAP}_{\mathrm{A} 2}$ and $\mathrm{CAP}_{\mathrm{A} 3}$ in nonREM sleep, which correlate with severity of symptoms of $\mathrm{FM}^{26}$. In addition, treatment with gamma-hydroxybutyrate (GHB) has been shown to reduce $\mathrm{CAP}_{\mathrm{A} 2}$ and $\mathrm{CAP}_{\mathrm{A} 3}$ and to improve symptoms of $\mathrm{FM}^{36}$. Together, these findings suggest that measuring $\mathrm{CAP}_{\mathrm{A} 2}$ and $\mathrm{CAP}_{\mathrm{A} 3}$ may be an improved surrogate for the physiological measure of unrefreshing or nonrestorative sleep in FM.

In our study, $\alpha$-EEG sleep and periodic $k-\alpha$ episodes were measured by observer-rating and CAP was measured by the Embla algorithm. The $\alpha$-nonREM sleep anomaly and periodic $\mathrm{k}-\alpha$ episodes were used at screening as inclusion criteria and also used in the sleep EEG analysis for treatment effects. Observer-rated $\alpha$-EEG sleep and periodic k- $\alpha$ were not significantly different between VLD CBP and placebo-treated subjects (data not shown). The lack of a response to CBP treatment in $\alpha$-EEG sleep or periodic k- $\alpha$ anomaly may relate to their imprecise rater measurements. The periodic k- $\alpha$ could not be individually analyzed with the Embla algorithm, since k- $\alpha$ is not isolated from the other features of $\mathrm{CAP}_{\mathrm{A} 2}$ and $\mathrm{CAP}_{\mathrm{A} 3}$, which include EEG arousals, and polyphasic bursts with $>20 \%$ to $50 \%$ and $>50 \%$ of EEG desynchrony, respectively. In contrast, a threshold for normalized $\mathrm{CAP}_{\mathrm{A} 2}+\mathrm{CAP}_{\mathrm{A} 3}$ or $\mathrm{CAP}_{\mathrm{A} 2+\mathrm{A} 3 \text { (Norm) }}$ was found to be informative for a potential treatment response since the percentage of patients with increased nights of $\mathrm{CAP}_{\mathrm{A} 2+\mathrm{A} 3 \text { (Norm) }}$ $\leq 33 \%$ or CAP response (ITT, LOCF) was $72 \%$ with VLD $\mathrm{CBP}$ vs $33 \%$ with placebo $(\mathrm{p}=0.019)$. The finding that $\mathrm{CAP}_{\mathrm{A} 2+\mathrm{A} 3(\mathrm{Norm})} \leq 33 \%$ may be a relatively healthy $\mathrm{CAP}_{\mathrm{A} 2+\mathrm{A} 3 \text { (Norm) }}$ value for patients with FM is consistent with our analysis of previously published normative data ${ }^{26}$.

For those receiving VLD CBP, the increase in nights with $\mathrm{CAP}_{\mathrm{A} 2+\mathrm{A} 3 \text { (Norm) }} \leq 33 \%$ correlates to change from baseline to Week 8 in fatigue, total HAD score, HAD depression score, and self-rated and clinician-rated change in fatigue. The correlation of nights with normal $\mathrm{CAP}_{\mathrm{A} 2+\mathrm{A} 3 \text { (Norm) }}$ and improvement with FM symptoms is consistent with the hypothesized effects of restorative sleep. The symptomatic benefit may relate to decreasing arousal signals during sleep. Together, these data show that the $\mathrm{CAP}_{\mathrm{A} 2+\mathrm{A} 3 \text { (Norm) }}$ rate may provide a novel biomarker for assessing treatment effects on nonrestorative sleep and associated subjective somatic and mood symptoms in FM. However, improvements in pain and tenderness did not appear significantly correlated with increased nights with $\mathrm{CAP}_{\mathrm{A} 2+\mathrm{A} 3 \text { (Norm) }} \leq$ $33 \%$. These findings will need to be studied in larger groups to determine whether the symptomatic improvements in pain and tenderness associated with VLD CBP treatment result from effects of $\mathrm{CBP}$ that are independent from improved sleep quality.

It is unclear how bedtime CBP exerted effects on various symptoms. FM is a chronic pain condition of complex etiology and pathogenesis. CBP is FDA-approved to treat muscle spasm. While muscle spasm is not a symptom of FM, the off-label use of CBP and several other muscle relaxants in FM suggests that muscle relaxant activity is a proxy for 1 or more activities relevant to treating FM symptoms. We recently reported that $\mathrm{CBP}$ is a potent inhibitor of 5-HT2a and the adrenergic $\alpha-2$ receptors $-\mathrm{A},-\mathrm{B}$, and $-\mathrm{C}^{37}$. Genetic linkages have associated FM with genes encoding 5-HT2a and adrenergic receptors ${ }^{38,39}$. In addition, ritanserin, another 5-HT2a receptor inhibitor, provided benefit to the sleep quality but not to pain or tenderness of patients with $\mathrm{FM}^{40}$. Further work is needed to determine the extent to which antagonism of 5-HT2a and $\alpha-2$ adrenergic receptors relates to the observed effects of bedtime VLD CBP on FM sleep physiology and symptoms.

Several observations suggest that 5-HT2a and $\alpha-2$ adrenergic inhibitors may be useful in improving sleep in FM. For example, 5-HT2a inhibitors have been associated with improvements in sleep quality in non-FM patients ${ }^{40,41}$. The inhibition of $\alpha-2$ adrenergic receptor by CBP may help modulate a hypersympathetic state in patients with FM, and the sympathetic nervous system has important effects on sleep $^{20,42}$. The effect of GHB on sleep, mood, and fatigue may be related to inhibition of central nervous system sympathetic neurotransmitter activities associated with arousal disturbances during sleep ${ }^{36}$. The effect of CBP decreasing $\mathrm{CAP}_{\mathrm{A} 2+\mathrm{A} 3}$ may be consistent with CBP's $\alpha-2$ antagonist activity. As a corollary of such an effect, recent observations show that clonidine, an $\alpha-2$ agonist, increases $\mathrm{CAP}_{\mathrm{A} 3}$ in patients with bruxism ${ }^{43}$. $\mathrm{CAP}_{\mathrm{A} 2}$ and $\mathrm{CAP}_{\mathrm{A} 3}$ are associated with an increase in sympathetic activities, such as event-related acceleration in heart rate and respiration during sleep. Future studies will explore the effect of bedtime $\mathrm{CBP}$ on heart rate variability and other measures that have revealed the role of hypersympathetic tone in FM.

Potential mechanisms for how bedtime CBP may improve FM symptoms are suggested by work on the sensation and regulation of pain in $\mathrm{FM}^{44}$. Comparisons of patients with FM and healthy controls by functional magnetic resonance imaging (fMRI) have correlated subjective pain thresholds with regional blood flow in the insula, anterior cingulate cortex, and the primary and secondary somatosensory corte ${ }^{44}$. Many observations link these regions to central pain perception and the regulation of pain perception by descending inhibition ${ }^{45,46}$. The response of FM patients relative to healthy controls to painful stimuli in fMRI regional blood flow are believed to provide objective evidence of heightened sensitivity to pain and deficiency in regulating pain perception by descending inhibition ${ }^{44,47,48}$. Personal non-commercial use only. The Journal of Rheumatology Copyright @ 2011 . All rights reserved. 
These fMRI studies suggest several steps at which CBP might correct processes that are abnormal or decompensated in FM. The descending inhibition of pain is known to be influenced by serotonin and norepinephrine ${ }^{46}$. Serotonin is thought to be directly involved in the central inhibition of pain: 5-HT1a receptors are thought to be antinociceptive, while 5-HT2a receptors are nociceptive. Consequently, as a 5-HT2a receptor inhibitor, CBP might be expected to increase descending inhibition of pain. Moreover, 5-HT2a receptors are upregulated with low-level tonic pain ${ }^{49}$, supporting the idea that antagonism of 5-HT2a might stimulate the pathway of descending inhibition in FM.

Although the mechanism by which bedtime VLD CBP acts remains unclear, our study demonstrates the potential for bedtime VLD CBP to relieve pain, reduce fatigue, decrease tenderness, improve mood, and improve sleep quality in patients with FM. $\mathrm{CAP}_{\mathrm{A} 2+\mathrm{A} 3 \text { (Norm) }}$ rate may provide a novel biomarker for assessing treatment effects on nonrestorative sleep and associated subjective somatic and mood symptoms in FM. Bedtime VLD CBP may have an advantage of decreased drowsiness relative to higher daytime doses. VLD CBP may have other advantages, since it is expected to have less potential for drug interaction or overdose, and may result in increased adherence as a result of once-daily dosing. Further studies will elucidate the extent to which CBP's antagonism of 5-HT2a and $\alpha-2$ adrenergic receptors relates to effects on FM symptoms and sleep physiology.

\section{ACKNOWLEDGMENT}

The authors gratefully acknowledge the contributions of Dr. Adam Moscowitz in providing subjects from the Calgary site; polysomnograhic technologists from the Calgary and Toronto sites; Brian Speicher, John Keogh, Steven Leventer, PhD, and Kevin Keim, PhD.

\section{REFERENCES}

1. Mease P, Arnold LM, Bennett R, Boonen A, Buskila D, Carville S, et al. Fibromyalgia syndrome. J Rheumatol 2007;34:1415-25.

2. Bennett RM, Gatter RA, Campbell SM, Andrews RP, Clark SR, Scarola JA. A comparison of cyclobenzaprine and placebo in the management of fibrositis. A double-blind controlled study. Arthritis Rheum 1988;31:1535-42.

3. Quimby LG, Gratwick GM, Whitney CD, Block SR. A randomized trial of cyclobenzaprine for the treatment of fibromyalgia. J Rheumatol Suppl 1989 Nov;19:140-3.

4. Reynolds WJ, Moldofsky H, Saskin P, Lue FA. The effects of cyclobenzaprine on sleep physiology and symptoms in patients with fibromyalgia. J Rheumatol 1991;18:452-4.

5. Santandrea S, Montrone F, Sarzi-Puttini P, Boccassini L, Caruso I. A double-blind crossover study of two cyclobenzaprine regimens in primary fibromyalgia syndrome. J Int Med Res 1993;21:74-80.

6. Cantini F, Bellandi F, Niccoli L, Di Munno O. [Fluoxetin combined with cyclobenzaprine in the treatment of fibromyalgia]. Minerva Med 1994;85:97-100.

7. Carette S, Bell MJ, Reynolds WJ, Haraoui B, McCain GA, Bykerk VP, et al. Comparison of amitriptyline, cyclobenzaprine, and placebo in the treatment of fibromyalgia. A randomized, double-blind clinical trial. Arthritis Rheum 1994;37:32-40.

8. Tofferi JK, Jackson JL, O’Malley PG. Treatment of fibromyalgia with cyclobenzaprine: A meta-analysis. Arthritis Rheum 2004; 51:9-13.

9. Iglehart IW. Methods for treating or preventing fibromyalgia using very low doses of cyclobenzaprine. 2003; US Patent 6,541,523.

10. Winchell GA, King JD, Chavez-Eng CM, Constanzer ML, Korn SH. Cyclobenzaprine pharmacokinetics, including the effects of age, gender, and hepatic insufficiency. J Clin Pharmacol 2002;42:61-9.

11. Darwish M, Hellriegel ET, Xie F. Single-dose pharmacokinetics of once-daily cyclobenzaprine extended release $30 \mathrm{mg}$ versus cyclobenzaprine immediate release $10 \mathrm{mg}$ three times daily in healthy young adults: a randomized, open-label, two-period crossover, single-centre study. Clin Drug Invest 2008;28:793-801.

12. Payne TC, Leavitt F, Garron DC, Katz RS, Golden HE, Glickman $\mathrm{PB}$, et al. Fibrositis and psychologic disturbance. Arthritis Rheum 1982;25:213-7.

13. Ahles TA, Yunus MB, Riley SD, Bradley JM, Masi AT. Psychological factors associated with primary fibromyalgia syndrome. Arthritis Rheum 1984;27:1101-6.

14. Wolfe F, Cathey MA, Kleinheksel SM, Amos SP, Hoffman RG, Young DY, et al. Psychological status in primary fibrositis and fibrositis associated with rheumatoid arthritis. J Rheumatol 1984;11:500-6.

15. Lewis T, Kellgren J. Observations relating to referred pain, visceromotor reflexes and other associated phenomena. Clin Sci 1939;4:47-71.

16. Bennett RM, Clark SR, Goldberg L, Nelson D, Bonafede RP, Porter $\mathrm{J}$, et al. Aerobic fitness in patients with fibrositis. A controlled study of respiratory gas exchange and 133-xenon clearance from exercising muscle. Arthritis Rheum 1989;32:454-60.

17. Russell IJ. Neurohormonal aspects of fibromyalgia syndrome. Rheum Dis Clin North Am 1989;15:149-68.

18. Moldofsky H. Chronobiological influences on fibromyalgia syndrome: Theoretical and therapeutic implications. Ballières Clin Rheumatol 1994;8:801-10.

19. Hawley DJ, Wolfe F, Lue FA, Moldofsky H. Seasonal symptom severity in patients with rheumatic diseases: a study of 1,424 patients. J Rheumatol 2001;28:1900-9.

20. Martínez-Lavín M, Hermosillo AG, Mendoza C, Ortiz R, Cajigas JC, Pineda C, et al. Orthostatic sympathetic derangement in subjects with fibromyalgia. J Rheumatol 1997;24:714-8.

21. Furlan R, Colombo S, Perego F, Atzeni F, Diana A, Barbic F, et al. Abnormalities of cardiovascular neural control and reduced orthostatic tolerance in patients with primary fibromyalgia. J Rheumatol 2005;32:1787-93.

22. Khasar SG, Dina OA, Green PG, Levine JD. Sound stress-induced long-term enhancement of mechanical hyperalgesia in rats is maintained by sympathoadrenal catecholamines. J Pain 2009; 10:1073-7.

23. Chervin RD, Teodorescu M, Kushwaha R, Deline AM, Brucksch CB, Ribbens-Grimm C, et al. Objective measures of disordered sleep in fibromyalgia. J Rheumatol 2009;36:2009-16.

24. Moldofsky H, Scarisbrick P, England R, Smythe H. Musculoskeletal symptoms and non-REM sleep disturbance in patients with "fibrositis" syndrome and healthy subjects. Psychosom Med 1975;37:341-51.

25. Moldofsky H, Scarisbrick P. Induction of neurasthenic musculoskeletal pain syndrome by selective sleep stage deprivation. Psychosom Med 1976;38:35-44.

26. Rizzi M, Sarzi-Puttini P, Atzeni F, Capsoni F, Andreoli A, Pecis M, et al. Cyclic alternating pattern: A new marker for sleep alteration in patients with fibromyalgia? J Rheumatol 2004;31:1193-9.

27. Rosa AC, Parrino L, Terzano MG. Automatic detection of cyclic alternating pattern (CAP) sequences in sleep: preliminary results. Clin Neurophysiol 1999;110:585-92. 
28. Wolfe F, Smythe HA, Yunus MB, Bennett RM, Bombardier C, Goldenberg DL, et al. The American College of Rheumatology 1990 criteria for the classification of fibromyalgia. Report of the Multicenter Criteria Committee. Arthritis Rheum 1990;33:160-72.

29. Rechtschaffen A, Kales A, editors. A manual of standardized terminology, techniques and scoring system for sleep stages of human subjects. Washington, DC: US Department of Health, Education, and Welfare Public Health Service - NIH/NIND; 1968.

30. MacLean AW, Lue F, Moldofsky H. The reliability of visual scoring of alpha EEG sleep. Sleep 1995;18:565-9.

31. Rosa A, Alves GR, Brito M, Lopes MC, Tufik S. Visual and automatic cyclic alternating pattern (CAP) scoring: inter-rater reliability study. Arq Neuropsiquiatr 2006;64:578-81.

32. Terzano MG, Parrino L. Clinical applications of cyclical alternating pattern. Physiol Behav 1993;54:807-13. Erratum in Physiol Behav 1994;55:199.

33. Parrino L, Smerieri A, Rossi M, Terzano MG. Relationship of slow and rapid EEG components of CAP to ASDA arousals in normal sleep. Sleep 2001;24:881-5.

34. Mease P, Arnold LM, Choy EH, Clauw DJ, Crofford LJ, Glass JM, et al; OMERACT Fibromyalgia Working Group. Fibromyalgia syndrome module at OMERACT 9: domain construct. J Rheumatol 2009;36:2318-29.

35. Terzano MG, Parrino L, Smerieri A, Chervin R, Chokroverty S, Guilleminault C, et al. Atlas, rules, and recording techniques for the scoring of cyclic alternating pattern (CAP) in human sleep. Sleep Med 2002;3:187-99.

36. Moldofsky H, Inhaber NH, Guinta DR, Alvarez-Horine SB. Effects of sodium oxybate on sleep physiology and sleep/wake-related symptoms in patients with FM syndrome: a double-blind, randomized, placebo-controlled study. J Rheumatol 2010; 37:2156-66

37. Harris HW, Lederman S. Cyclobenzaprine (CBP) is a potent antagonist of serotonin receptor 2a (5-HT2a) and $\alpha$-2 adrenergic receptors: mechanistic implications for promoting restorative sleep in fibromyalgia syndrome (FMS) [abstract]. Arthritis Rheum 2010;62 Suppl:799.

38. Lee YH, Choi SJ, Ji JD, Song GG. Candidate gene studies of fibromyalgia: a systematic review and meta-analysis. Rheumatol Int 2010 Dec 1. [E-pub ahead of print]
39. Vargas-Alarcón G, Fragoso JM, Cruz-Robles D, Vargas A, Martinez A, Lao-Villadóniga JI, et al. Association of adrenergic receptor gene polymorphisms with different fibromyalgia syndrome domains. Arthritis Rheum 2009;60:2169-73.

40. Olin R, Klein R, Berg PA. A randomised double-blind 16-week study of ritanserin in fibromyalgia syndrome: clinical outcome and analysis of autoantibodies to serotonin, gangliosides and phospholipids. Clin Rheumatol 1998;17:89-94.

41. Landolt HP, Wehrle R. Antagonism of serotonergic 5-HT2A/2C receptors: mutual improvement of sleep, cognition and mood? Eur J Neurosci 2009;29:1795-809.

42. Ouyang M, Hellman K, Abel T, Thomas SA. Adrenergic signaling plays a critical role in the maintenance of waking and in the regulation of REM sleep. J Neurophysiol 2004;92:2071-82.

43. Carra MC, Macaluso GM, Rompré PH, Huynh N, Parrino L, Terzano MG, et al. Clonidine has a paradoxical effect on cyclic arousal and sleep bruxism during NREM sleep. Sleep 2010;33:1711-6.

44. Gracely RH, Petzke F, Wolf JM, Clauw DJ. Functional magnetic resonance imaging evidence of augmented pain processing in fibromyalgia. Arthritis Rheum 2002;46:1333-43.

45. Craig AD. How do you feel - now? The anterior insula and human awareness. Nat Rev Neurosci 2009;10:59-70.

46. Ossipov MH, Dussor GO, Porreca F. Central modulation of pain. J Clin Invest 2010;120:3779-87.

47. Cook DB, Lange G, Ciccone DS, Liu WC, Steffener J, Natelson $\mathrm{BH}$. Functional imaging of pain in patients with primary fibromyalgia. J Rheumatol 2004;31:364-78.

48. Jensen KB, Kosek E, Petzke F, Carville S, Fransson P, Marcus H, et al. Evidence of dysfunctional pain inhibition in fibromyalgia reflected in rACC during provoked pain. Pain 2009;144:95-100.

49. Kupers R, Frokjaer VG, Naert A, Christensen R, Budtz-Joergensen E, Kehlet H, et al. A PET [18F] altanserin study of 5-HT2A receptor binding in the human brain and responses to painful heat stimulation. Neuroimage 2009;44:1001-7. 